dissociation of sensory defects is well illustrated; the spastic gait is probably a merely secondary phenomenon, though the patient states that a practitioner in Philadelphia said he had amyotrophic lateral sclerosis. Most interesting is the question as to what determined the development of the central degeneration in the cord, though it would be too large for aiscussion here. The patient, except for the difficulty which he has in putting on his clothes and feeding himself, is in good general bealth and complete mental activity.

Westland-row, Dublin.

\section{SHORT NOTES OF A TEN-MONTHS' ILLNESS.}

\section{BY S. WILSON HOPE, L.R.C.P. LOND., M.R.C.S. ENG.}

IN August, 1891, a man aged sixty, well built, of active habits, and whose only serious disturbances of health for twenty or thirty years (excepting an abscess near the ear, for which Dr. Urban Pritchard made an incision in the floor of the eanal) had been occasional attacks of sleeplessness, with or without depression, besides an indescribable cough, which dated back to measles in childhood and was thought little of, songht advice for the following ills: swelling and pain in some of the joints of the fingers; pain over the region of the heart, which sometimes shifted over to the right chest-wall; shortness of breath and sleeplessness, along with some depression. He looked a little anxious and "out of sorts." His pulse was markedly compressible and intermittent. His tongue was clean. There was nothing to be noticed about the heart, except that it was acting weakly and irregularly, nor was there anything the matter with the urine, except that I think that his arthritic troubles would have been better had it shown a good pink sediment. Leaving these grosser organs for the brain, it was ascertained that he had been very anxious of late, on account of business worries. On the whole, then, the case came to be looked upon as a work-and-worry breakdown-a form of neurasthenia; he was given nervine tonics, sleep being obtained by drugs, and change was ordered at once, his gout, if gout it were, being ignored. He decided to go to Deal as soon as he could get away, for there he had once before obtained benefit when attacked by sleeplessness. He left on Sept. 20th, with instructions to take an opinion in town upon his case and nothing more was heard of him till the receipt of the following letter from the physician he consulted "Oct. 16th, 1891.-Mr. - consulted me this morning. $\mathrm{He}$ is evidently much worse than when you last saw him before he went to Deal and has the aspect of a stricken man. He has lost flesh, colour and strength, and is so short of breath that he can scarcely walk 100 yards. The pulse is weak and frequent, and he has a cough, which, he says, is recent. It is difficult to explain his condition by what is found on examination. The abdominal organs appear to be fairly normal; the impulse and sounds of the heart are weak, but I find no definite disease. At the base of the right lnng there is dulness from the angle of the scapula downwayds posteriorly, extending round the lateral aspect of the chest at a lower level to the sternum. Air does not enter well over this area and on deep inspiration a few large crepitations can be heard, with obscure and distant tubular breathing. There is no exaggerated vocal resonance and vibration, such as wonld attend consolidation, and, on the other hand, the signs are not those of pleural effusion. I am disposed to think that here is the disease underlying the symptoms, but I cannot give a definite diagnosis of its nature. There is, however, much which is suggestive of malignant infiltration (sarcoma). I have seen no temperature records; the rigor was probably (?) pyrexial, its occurrence militates against the idea of malignancy, and I have had no opportunity of examining the arine, which might throw light on the case. There remains the question of the relation of the gout in the hands to the general condition; but for this, I should have recommended iron and quinine. On the chance that gout may have played an important part, it may be safe to give alkalies and tonics, and I enclose a prescription by way of suggestion. Iodine or a blister might be applied to the dull area. - Yours faithfally, _-.." Again, on Oct. 8th, 1892, the same physician wrote : "I consider it imperatively necessary that Mr. should have at least three or four months of rest ; possibly a longer period may be required. I hope there is not malignant disease, and there are several points which are not like cancer or sarcoma, among them the information you give as to the causation and mode of onset of the illness. The aspect, the aggravation of the symptoms, and increase of weakness when at the seaside, together with the irritable cough, were the facts which seemed to point to a serious interpretation of the physical signs. Yours, \&c.- "This advice was steadily followed for some time, though Mr. - could not be persuaded to apply for three or four months' leave of absence. No progress being made, he was given iron, arsenic and digitalis, and for a few weeks he gained weight, but in other ways remained about the same, though he was certainly stronger than when he returned from Deal. He could not use his hands well; wrote with difficulty, even with a specially constructed penholder; and never attempted to touch his violin. He moved about the house and walked out in suitable weather, the cough also being much better; but he made no progress; nor were matters improved by continued business anxiety. Patience gave way to despair. He determined to try a system pressed upon him by some friends, and originated by some lady whose name I forget. The chief points in this system, as set forth in a book on the cure of gout, were a flesh diet and copions draughts of water. My attendance ceased. In about ten days I was recalled and found that he had taken to his bed, with a temperature of $103^{\circ}$, frequent and distressing cough, and copious expectoration. He gave up all hope and day after day seemed to be slowly settling down. The feet and legs became swollers; breathing was difficult; the joints were painful; the tongue was glazed, and the pulse was very feeble. It was then deemed possible that all his troubles might be caused by some noxious element in the blood which none of the purifying organs could eliminate. If so, might not the inhalation of oxygen, by supplementing the crippled lung, aid very much in breaking this ingredient up into some more manageable molecules? Oxygen was given three times a day, and after a week or two the urine became loaded with lithates and colouring matter, and remained so for a great many days. Then improvement set in all round, and steadily, without any check, the patient recovered his health so far as to be able to get about and enjoy life once more, nor has anything worse than a broken leg befallen him since.

Petworth, Sussex.

\section{SOME REMARKS ON THE USE OF IODOFORM IN SURGERY}

\section{BY R. H. ANGLIN WHITELOCKE, M.B., C.M. EDIN.,} F.R.C.S. ENG.

Now that the use of iodoform in surgery bids fair to be discontinued in the practices of some surgeons-the complaints being in some cases directed against its objectionable odour, in others to the circumstance that doubts have been entertained as to its efficacy as an antiseptic substance-it was with no small measure of interest that I recently read an article in THE LANCET, entitled "One of the Best Applications of Iodoform in Surgery," from the pen of Mr. Arbuthnot Lane. ${ }^{1}$ In his paper he brings forward its claims in a new light. His method of "stamping in" the purified powder into carious bone cavities as a dentist would fill a tooth is alike ingenious and novel and adds a more or less mechanical application to its more customary usages. Not only does he claim for his method the advantage of displacing the blood-clot, which would of necessity form and be a source of great danger in tuberculous cases, but also that of its being capable of entering into the formation of a restored osseous framework. That such does seem to be the case the citation of his cases, so eminently successful, goes far towards establishing. One of the reasons which urges me to write this paper is that the subject has been for some time of particular interest to myself. So long ago as the autumn of 1886, when I enjoyed the privilege of being house surgeon to Professor Macewen in Glasgow, I learned in a measure this use of iodoform. It was then the custom, and I know it was for some considerable time later, for that surgeon to fill up all the existing cavities in bones

1 The Lancet, July 15th, 1893. 